\title{
TEORIA SOCIAL, EXTROVERSÃO E AUTONOMIA: impasses e horizontes da sociologia (semi)periférica contemporânea
}

\author{
Breno Bringel ${ }^{\star}$ \\ José Maurício Domingues ${ }^{* *}$
}

\begin{abstract}
Este artigo analisa a produção de teoria social na periferia em diferentes eras geopolíticas e fases da modernidade, com ênfase especial para a sociologia semi(periférica) contemporânea. Argumenta-se que a agenda de pesquisa atual gira ao redor de um movimento intelectual de crítica destituinte do eurocentrismo e da modernidade, sem conseguir, no entanto, criar formulações teórico-metodológicas sistemáticas, como ocorreu a meados do século XX. Busca-se, portanto, avançar nas bases para a construção de um movimento instituinte mais propositivo a partir de duas direções: por um lado, recuperando a centralidade de campos autônomos e circuitos agregadores que superem a extroversão intelectual; e, por outro, analisando, em diálogo com Guerreiro Ramos, as possibilidades de construção de teoria na (semi)periferia como uma das principais chaves para deslocar, de maneira mais permanente, a hegemonia das teorias dos países centrais e seu uso habitualmente protocolar fora de seu solo original.

Palavras-chave: Teoria sociológica. Semi(periferia). Modernidade global. Guerreiro Ramos. Epistemologia.
\end{abstract}

\section{INTRODUÇÃO}

Existe uma relação intrínseca entre as "eras geopolíticas" (Agnew e Corbridge, 1995; Cairo, 2008) e a emergência de "geopolíticas do conhecimento" (Mignolo, 2002), que configuram um olhar das ciências sociais, e particularmente da sociologia, para lugares e temas específicos. Em outras palavras, a existência, em diferentes momentos históricos, de sucessivas ordens geopolíticas, com suas respectivas regras, instituições, rotinas e relações de poder, guarda uma estreita relação com o desenvolvimento da sociologia no mundo em

\footnotetext{
* Doutor em Ciência Política e Sociologia. Professor-pesquisador do IESP-UERJ. Bolsista de Produtividade do CNPq e Jovem Cientista do Nosso Estado - FAPERJ.

Rua da Matriz, 82. Cep: 22260100. Botafogo - Rio de Janeiro - Rio de Janeiro - Brasil. brenobringel@iesp.uerj.br

** PhD em sociologia pela London School of Economics and Political Science. Professor-pesquisador do IESP -UERJ. Bolsista de Produtividade do CNPq 1B e Cientista do Nosso Estado - FAPERJ.

Rua da Matriz, 82. Cep: 22260100. Botafogo - Rio de Janeiro - Rio de Janeiro - Brasil. jmdomingues@iesp.uerj.br

1 Este artigo é parte de um esforço intelectual mais amplo de discussão sobre a sociologia latino-americana $e$ a construção de teoria na periferia, realizado no Núcleo de Estudos de Teoria Social e América Latina (NETSAL), coordenado por nós no IESP-UERJ (http://netsal.iesp.uerj. br/). Agradecemos o diálogo dos pesquisadores do NETSAL, conquanto a responsabilidade do texto seja exclusivamente nossa.
}

termos de modalidades, práticas, alcances e gramáticas da disciplina.

A origem e a formação da sociologia na Europa constituem uma mostra disso e refletem como a "imaginação geopolítica" moderna está entrelaçada com a "imaginação sociológica” emergente no continente, impregnada de noções como civilização, progresso, razão ou nação. Se a sociologia, considerada como um produto histórico e especializado, era um privilégio dos países centrais nessa primeira fase da modernidade, marcada por um caráter liberal limitado e pela expansão colonial ocidental para além das Américas (Domingues, 2009), tudo o que se produzia na América Latina era qualificado como ensaísmo, pensamento présociológico ou "protossociologia" - em alguns casos de forma depreciativa ou, por outro lado, acompanhado de uma exigência de superação (Germani, 1959). Embora a recepção da sociologia europeia e, posteriormente, norte -americana, durante boa parte do século XIX e, principalmente, primeira metade do século $\mathrm{XX}$, nunca tenha sido totalmente passiva ou acrítica nos países periféricos, nota-se uma importante guinada durante a década de 1950 
e 1960, que já vinha se construindo de maneira paulatina, ao menos desde os anos 1930.

O início de uma nova ordem geopolítica marcada pela Guerra Fria, em meados do século XX, se dá, de fato, de forma concomitante a uma aposta crescente pelo descentramento do pensamento sociológico. A emergência de um "Bandung intelectual", na segunda fase da modernidade, fortemente organizada pelo Estado, produziu-se vis-à-vis às lutas anticoloniais na África e na Ásia, aos movimentos revolucionários na América Latina e à difusão dos nacionalismos periféricos e da narrativa desenvolvimentista. O desejo de emancipação frente a uma ordem dominante e discriminadora orientava esses esforços. A articulação entre teoria e prática, o questionamento dos limites do eurocentrismo, a recepção e a assimilação crítica da sociologia central, a autonomização da sociologia como disciplina e a necessidade de construir instituições e debates próprios dos contextos periféricos foram somente alguns dos principais leitmotivs da sociologia terceiro-mundista em sua busca por uma ciência autóctone, autônoma e nacional. Circuitos nacionais e regionais de produção e circulação do conhecimento foram criados e houve um considerável avanço em termos de teorizações abrangentes, processuais e globais da sociedade, que geraram, inclusive, um novo repertó뇯 rio conceitual associado à mudança social e ao debate sobre o colonialismo, o imperialismo, o

$\therefore$ derrotadas) coincidiram, no plano global, com

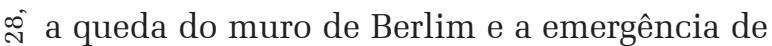

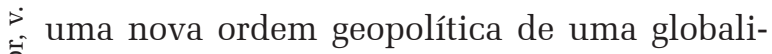
zação neoliberal militarizada, e com o retorno da hegemonia dos circuitos de produção e circulação do conhecimento das ciências sociais. Embora as forças hegemônicas, circunscritas à narrativa do there is no alternative, tendessem a reproduzir práticas, discursos e repre- sentações do espaço homogeneizantes, várias foram as resistências e os padrões de contestação globalmente orientados, conquanto com força e inspiração fortemente enraizadas em lugares e países da periferia mundial (Bringel, 2015). Imersos já na terceira fase da modernidade - mais descentrada, heterogênea e complexa que as anteriores -, vemos como a crise das ciências sociais e da intelectualidade, de maneira mais geral ocupada em dar respostas ao agravamento dos problemas sociais, políticos e econômicos, acontece de forma paralela à crescente crítica aos centros hegemônicos de poder e saber e à afluência de atores políticos e sociais que buscam incidir no debate público. A emergência de novos governos progressistas na América Latina, a centralidade das lutas dos movimentos sociais e as novas formas de solidariedade e práticas articulatórias "SulSul”, institucionais e não institucionais, dão lugar a inovadores, embora ainda precários e fragmentados, espaços transnacionais de experimentação, troca e pensamento coletivo.

De forma paralela a essa guinada geopolítica, com a emergência de novos movimentos populares e, em parte, de uma nova semiperiferia global, a discussão sobre o "Sul" e a "(semi)periferia” volta a ganhar centralidade nas últimas décadas em todo o mundo (revestida agora, como veremos, de novas etiquetas como a de "Sul Global"). E vai chegando aos poucos ao Brasil. A despeito da convergência de alguns denominadores comuns relacionados à produção e à circulação assimétrica do pensamento sociológico e à centralidade do colonialismo no descentramento da disciplina, trata-se de um movimento intelectual bastante heterogêneo. As etiquetas utilizadas (teorias ou epistemologias do Sul; sociologia periférica; sociologia global; teorias pós-coloniais, etc.) também são diversas e partem de pressupostos teórico-metodológicos distintos que projetam interpretações diferentes sobre a modernidade, o legado do colonialismo e o papel da sociologia.

Dentro dessa ampla gama de propostas, 
é importante reforçar que a emergência das “agendas pós-coloniais" contemporâneas está profundamente associada a uma possível transição global das ciências sociais (Patel, 2015) e à reconfiguração dos processos globais de desenvolvimento, às novas alianças geoculturais e geoestratégicas, às práticas e políticas de cooperação internacional, à crítica ao eurocentrismo, ao realinhamento dos blocos de integração regional e às novas gramáticas sociais emergentes.

Em trabalhos prévios, analisamos criticamente as possibilidades e limites dessas agendas pós-coloniais e periféricas na geração de novos quadros interpretativos para o estudo da teoria social (Domingues, 2003, 2011 e 2013), dos movimentos sociais (Bringel, 2011) e das imbricações entre modernidade e contestações sociais (Bringel e Domingues, 2012 e 2015). De maneira sintética, pode-se afirmar que boa parte dessa agenda de pesquisa emergente, embora realize uma pertinente crítica epistemológica à produção e circulação de conhecimento, não consegue sugerir alternativas ao eurocentrismo em termos de formulações teórico-metodológicas, tal como ocorreu na periferia em meados do século XX. A crítica ao provincianismo mascarado de universalismo é fundamental, mas igualmente importante é avançar para além da denúncia, rumo a uma teorização sistemática que permita gerar marcos mais robustos e abrangentes de interpretação das realidades periféricas e semiperiféricas a partir de uma perspectiva totalizante que transcenda o empirismo localizado.

Sob esse pano de fundo, este artigo pretende contribuir para o debate sobre os impasses e os horizontes da sociologia (semi)periférica contemporânea sugerindo que é preciso dar um passo além do que aqui denominaremos como pensamento destituinte, ou seja, aquelas correntes intelectuais cujo foco central é a crítica ao eurocentrismo e a destituição de suas bases epistemológicas, limitadas em sua dimensão propositiva. Busca-se aqui resgatar elementos presentes na tradição da sociologia central e na sociologia periférica da segunda metade do século XX, que permitam progredir na construção de circuitos autônomos e perspectivas próprias de um movimento intelectual instituinte. À diferença de outros textos deste mesmo dossiê sobre Guerreiro Ramos, que também tratam essa questão a partir de uma discussão meticulosa dos aportes do autor baiano - seja para inscrevê-lo no campo da dita sociologia periférica ${ }^{1}$ seja para reconstruir sua proposta de teoria da sociedade brasileira -, optamos aqui por um movimento mais abrangente, em cujo seio Ramos aparecerá mais pontualmente, principalmente na segunda metade do texto, como provocador de discussões ainda altamente vivas e instigantes.

O artigo está dividido em quatro partes, além desta introdução. Em primeiro lugar, na seção seguinte, situaremos, de maneira geral, algumas das principais propostas associadas à reconstrução da sociologia periférica e semiperiférica contemporânea, ressaltando suas particularidades, potencialidades e limitações. Em segundo lugar, retoma-se a clássica discussão sobre heteronomia, campos e extroversão intelectual para problematizar os condicionantes estruturais e as bases necessárias para a geração de um campo ou movimento intelectual de caráter autônomo, propositivo e agregador. Como consequência, discutem-se, em terceiro lugar, as complexidades e contradições dos circuitos intelectuais periféricos e semiperiféricos, particularmente sua constituição em "comunidades imaginadas" que mobilizam o nacionalismo como narrativa política e como dispositivo metodológico circunstancial. Finalmente, analisamos as possibilidades de construção de teoria na (semi)periferia como uma das principais chaves para deslocar, de maneira mais permanente, a hegemonia das teorias dos países centrais e seu uso habitualmente protocolar fora de seu solo original.

1 Para esforços nessa direção, ver os artigos recentes de João Marcelo Maia, tais como Maia (2012). 


\section{O pensamento pós-colonial e a so- ciologia periférica contemporânea como crítica destituinte}

Os estudos pós-coloniais, assim como outras propostas de sociologia "indígena" (Akiwowo, 1988; Adesina, 2002), "global" (Turner, 1989; Bhambra, 2013), "do Sul” (Connell, 2007; Santos, 2009) e outros rótulos, como "cosmopolita", "endógena" e "autônoma”, têm chamado crescentemente a atenção das ciências sociais contemporâneas pelas suas propostas de descentramento da sociologia e da modernidade. Trata-se de um movimento intelectual bastante amplo, heterogêneo e diferente daquele que, ao calor das lutas políticas de meados do século XX, consagrou um dos momentos mais criativos do pensamento latino-americano e fixou bases fundamentais para uma sociologia crítica na África e na Ásia.

As noções de Terceiro Mundo e de periferia, tão fortes naquele momento, dão lugar, hoje, a outras como a de "Sul Global" que, na maioria dos casos, não é mais que um sinônimo aggiornato das anteriores, referindo-se, assim, a "um conjunto mais ou menos heterogêneo, do ponto de vista cultural e político, de países, que, no entanto, compartilham uma posição estrutural de periferia ou semiperiferia no sistema mundial" (Cairo e Bringel, 2010, p. 43).

$\stackrel{2}{5}$ Diante de um Sul Global, haveria sempre um Norte Global, o que nos leva não a um terreno de uma geografia física, mas de uma geografia moral e estrutural que tem sido ampliada, para além dos processos sociopolíticos, à divisão internacional do trabalho acadêmico. Como também sugeriram Cairo e Bringel (ibidem), ¿ o Sul Global não está constituído como tal na i̊ atualidade. Existem somente processos de artiثิ culação, que não se produzem aleatoriamente nem em abstrato, mas em função de campos de proximidade geográfica, afinidades geoculturais e eixos de convergência, sejam eles teóricos, políticos ou epistêmicos. Ademais, se consideramos países como a China, cujos olhares e desejos - e o de seus intelectuais - se dirigem exclusivamente aos Estados Unidos e à Europa, salvo quando se engajam de forma instrumental com o restante da semiperiferia e a periferia, a própria validade do termo se põe em cheque, demandando conceituações mais precisas (Wang, 2011).

À diferença dos circuitos intelectuais relativamente integrados, existentes na periferia mundial entre as décadas de 1950 e 1970, esses processos de articulação contemporâneos apresentam-se mais como verdadeiros arquipélagos, ou seja, como conjuntos de ilhas próximas, mas que não por isso se conectam realmente. Em vez de uma agenda de pesquisa compartilhada, que permita uma base comum de construção teórico-metodológica passível de geração de novos conceitos, temos uma multiplicidade de propostas fragmentadas, geralmente de caráter destituinte mais que instituinte, que colocam em questão o caráter emancipatório da modernidade, e junto com ela, o da própria sociologia. Não se pode confundir a sociologia (semi)periférica - entendida aqui como a estruturação de um pensamento sociológico metódico, orientado a pensar as sociedades e a modernidade global a partir da (semi)periferia (Domingues, 2011 e 2013; Bringel e Domingues, 2015) -, com sociologia na periferia. O que há, na atualidade, de maneira mais expressiva, são tentativas de "periferialização sociológica", marcadas por buscas de "descolonização" da sociologia europeia (Boatca, Costa e Gutiérrez-Rodríguez, 2010) e sua "provincialização" no seio de uma história global e conectada (Chakrabarty, 2000). É importante notar que a noção de "periferia" não tem sido mobilizada em seu potencial analítico, como outrora fizeram autores como Raul Prebisch, Celso Furtado, Cardoso e Faletto, Johan Galtung, Giovani Arrigui, Immanuel Wallerstein e, inclusive, Niklas Luhmann. O próprio Guerreiro Ramos contribuiu para esse debate (1995 [1958], p.65 e 260). Por um lado, alertou, apropriando-se de Weber, que toda sociedade pode se distinguir entre centro e periferia, sendo o primeiro a região a partir da qual se logra 
conformar o complexo social e estabelecer as pautas da sociedade, embora seja preciso matizar que nem a periferia é passiva nem o centro homogêneo. Por outro, sugere que a centralidade da diferenciação entre centro e periferia não pode nos coibir de buscar uma teoria globalista da sociedade e de nossa época.

Outrossim, a sociologia periférica não deveria se basear em certidões de nascimento, mas sim no compromisso com a elaboração de determinados debates e agendas intelectuais. Autores de origem europeia, como José Medina Echevarría, ou Andre Gunder Frank, entre muitos outros, contribuíram enormemente, em meados do século XX, para o avanço da sociologia latino-americana e periférica, de maneira geral. Por outro lado, muitos autores aqui nascidos, baseados dentro ou fora da América Latina, pouco contribuem para a estruturação de uma teorização crítica sobre a sociedade na região. De fato, inclusive vários dos afiliados às correntes pós-coloniais, embora provenientes do Sul, acabam sucumbindo às lógicas impostas pelos debates existentes do Norte, mesmo que sua intenção fosse descolonizar as ciências sociais. Como sugere Burawoy (2015), quando as teorias viajam, seus significados podem ser radicalmente transformados, dependendo não somente da teoria em si, mas do contexto de recepção. Isso tem levado a que muitas das "teorias do Sul", quando chegam ao norte, percam seu potencial original e crítico, sendo inseridas em debates mais amplos da academia do centro, a partir de dinâmicas constantes de canonização e legitimação.

Poder-se-iam diferenciar, em termos estritamente analíticos, as tentativas de reconstruir a sociologia na periferia e na semiperiferia contemporânea, tanto por critérios geográficos e temáticos como por alinhamentos a matrizes político-ideológicas e tradições intelectuais. Foge do escopo deste artigo realizar uma análise detida dos autores e escolas, mas faz-se importante situar alguns pontos convergentes e divergentes dessas correntes, com o objetivo de localizar possíveis sinergias e possibilida- des de construção de uma sociologia periférica mais articulada e instituinte na atualidade. ${ }^{2}$

Vale mencionar, de qualquer modo, em primeiro lugar, uma corrente que tem como foco a realidade latino-americana. Trata-se de autores como Aníbal Quijano, Walter Mignolo, Edgardo Lander, entre outros, que consideram que, após o colonialismo, regiões como a América "Latina" continuaram expostas à colonialidade do poder (da política e da economia), do saber (em termos epistêmicos, filosóficos e científicos) e do ser (afetando a sexualidade ou as subjetividades). Dentro da perspectiva da colonialidade do saber, há uma relação intrínseca entre lugar de enunciação e a produção de conhecimentos. ${ }^{3}$ Sua contribuição tem se fragmentando como programa coletivo nos últimos anos, devido a divisões internas e a sua própria heterogeneidade.

Esta é, aliás, uma característica comum dos estudos pós-coloniais contemporâneos, o que lhes tem impedido a construção de debates convergentes no médio e no longo prazo. É o caso da denominada escola de "estudos subalternos" indiana, estimulada inicialmente por Ranajit Guha e dentro da qual inserem-se autores tão diversos como Dipesh Chakrabarty, Gayatri Spivak, Partha Chatterjee e Sumit Sarkar. Iniciando-se no marxismo, alguns de seus componentes, ao migrarem para os Estados Unidos, adotaram, em larga medida, o pós-estruturalismo, ao passo que outros, em geral ainda baseados na Índia, mantiveram sua inspiração marxista original (ver Sarkar, 1997; Lal, 2001). Importa aqui não somente o lócus de onde se produz conhecimento como também quem o produz, com ênfase para os atores subalternizados que impulsionam processos de transformação social.

No caso do continente africano, a despeito dos intelectuais vinculados à negritu-

${ }^{2}$ Ver, de maneira geral, Devés-Valdés, 2014, que realiza, de fato, um painel comparado do "pensamento periférico", considerado de uma perspectiva "eidética”, isto é, fenomenológica e descritiva

${ }^{3}$ Ver Domingues, 2011, cap. 2, para uma discussão crítica dessa corrente, em especial da obra de Mignolo, marcando, porém, suas diferenças internas, inclusive geracionais 
de e ao pan-africanismo (incluindo nomes como os de Franz Fanon, Mario de Andrade, Cheikh Anta Diop, Léopold Sédar Senghor, Chinweizu, Nkrumah, Aimé Césaire), não é possível falar de um "grupo" ou "movimento intelectual" relativamente delimitado ou estruturado que articule as vozes da sociologia africana em termos de sociologia periférica, com a exceção, talvez, do Conselho para o Desenvolvimento da Pesquisa em Ciências Sociais na África (CODESRIA), criado em 1973 com o intuito de combater a fragmentação de conhecimento sociológico na África. Uma das contribuições mais importantes dos intelectuais africanos tem sido a discussão sobre o racismo como uma característica constitutiva da "razão helênica” que, com sua visão universal, levaria à construção de oposições binárias entre o moderno e o tradicional, nublando o potencial epistêmico de configurações locais de pensamento, tanto na produção como na circulação de conhecimento, difundido, no caso africano, principalmente por meio da oralidade. É justamente esse ponto que leva a que Akiwowo (1988) proponha uma reconstrução da sociologia africana a partir da literatura oral, buscando construir conceitos e teorias que permitam captar as visões de mundo, as condições de existência, a unidade da vida em comunidade e os problemas sociais da região. Com sua proposta

농 $\mathrm{O}$ autor influenciou enormemente a construção ָे de uma "sociologia indígena" com pretensões ¿ teóricas e universalistas, visão bem diferente ్ㅡㅁ à de certa "sociologia endógena", nativa, particularista e com uma compreensão baseada em ถึ.

D De forma paralela a esse levantamento a tectônico do Sul, emergem várias outras pro$\stackrel{\infty}{\sim}$ postas, algumas das quais situadas no Norte geográfico e que dialogam com a sociologia central contemporânea, especialmente a partir das guinadas (turns) culturalistas, discursivistas, pós-estruturalistas e pós-modernas. As teorias do Sul (Connel, 2007; Santos, 2009), por exemplo, recuperam a sociologia do conhecimento e tradições sociológicas nacionais diversas para tentar compor e elaborar um mapa mais complexo do que seria a produção teórica para além dos países centrais. Linha similar é seguida pelas propostas de uma "sociologia global”, conquanto não pareça suficiente simplesmente construir um mosaico de sociologias nacionais para falar de uma sociologia desse tipo (Burawoy, 2005).

Em perspectiva comparada, algumas contribuições convergentes e fios condutores aparecem: o questionamento dos diferentes "legados" do colonialismo (culturais, históricos, geográficos) e de suas formas de persistência na atualidade; o horizonte normativo de construção de "epistemologias alternativas" que questionam o caráter patriarcal, racista, capitalista e eurocêntrico da modernidade e suas formas de conhecimento; a recuperação e visibilização de experiências silenciadas; o restabelecimento de uma fronteira mais tênue entre o objeto e o sujeito de estudo; a abertura a outros lócus de produção de conhecimento, exterior às universidades, e a legitimação desses atores e espaços.

Embora essas sejam questões fundamentais, vários problemas também parecem ser recorrentes nessas propostas: um primeiro problema é a geração de novas canonizações e etiquetas. Dentro dos esforços recentes do pensamento pós-colonial, corre-se o risco de criar etiquetas rígidas e novos referenciais obrigatórios e de legitimação que acabam nublando a busca de novas articulações teóricas e epistemológicas, além de, em alguns casos, descontextualizar os aportes de autores periféricos que são (re)canonizados pelo centro. Uma segunda questão é o tratamento pouco rigoroso da noção de epistemologia e de sua relação com a teoria e a construção de inovações para o entendimento da vida social (adiante voltaremos a isso).

Ainda assim, contrariando a proposta de dar voz aos oprimidos e subalternos, em muitos casos, há uma leitura pouco indutiva de práticas, experiências e realidades sociais que não são estudadas a fundo, mas são utilizadas e (ou) apropriadas para justificações epistemo- 
lógicas mais amplas. Tal como sugeriu Bringel (2011), é habitual ver como os zapatistas ou o MST converteram-se, no mundo, em exemplos quase obrigatórios para um amplo número de autores que se autoidentificam com as interpretações pós-coloniais e consideram, de maneira superficial, esses movimentos como geradores de "outros conhecimentos" e "outras racionalidades", ainda que não se aprofunde a análise de como ocorre esse processo, nem se debata a agência e as contradições. Finalmente, o entendimento limitado, por parte de alguns desses autores, dos lugares periféricos como espaços praticamente exteriores à modernidade e a rejeição de tudo que provém do Norte implicam não reconhecimento do outro e potencialidade das conexões e articulações globais. Isso acaba gerando, em alguns casos, um abandono de qualquer pretensão universalista e uma criação de novos provincianismos, bem como de propostas muito orientadas para a prática, que acabam descurando da análise teórica.

Seja como for, a sociologia (semi)periférica contemporânea - independentemente de suas vertentes temáticas e geográficas, heterogeneidade e fragmentação - tem contribuído bastante para a negação e a problematização de certos consensos e convenções. No entanto, em geral, ainda é bastante reativa e destituinte, posto que o objetivo último, em muitos casos, é a crítica ao eurocentrismo, entendida como um fim em si mesmo, e não como um meio para alcançar, por exemplo, outras formas de construção do pensamento sociológico. A nosso ver, esse papel de denúncia e crítica deve, no entanto, ser acompanhado de uma agenda mais proativa na construção de teoria. Além disso, apesar da multiplicidade de propostas periféricas intelectuais circulando na atualidade, ainda não temos nada parecido a um "Bandung intelectual do século XXI". Isto não se deve, no entanto, somente à heterogeneidade de perspectivas aqui apontadas, pois, afinal, a pluralidade e a diversidade são elementos positivos para a construção do pensamento crítico. O motivo principal dessa polissemia fragmentada de vozes ao Sul continua sendo a escassez de circuitos regionalizados e de campos intelectuais relativamente autônomos que permitam a troca sistemática, a pesquisa conjunta sobre temas convergentes e o contraste de ideias.

\section{Autonomia, campos e extroversão: bases para um movimento intelectu- al instituinte}

Na teoria de Pierre Bourdieu (1992), os "campos", embora cada um deles sempre em comunicação com outros campos e em relações de disputa com eles, são ou devem ser, para serem assim adequadamente caracterizados, capazes de manter sua autonomia de maneira mais ou menos clara e intensa. Isso significa a existência de parâmetros internos próprios. Tendo isso em vista, pode-se sugerir a hipótese de que, em contrapartida, em países periféricos e semiperiféricos, bem como dependentes, isso é muito mais difícil e improvável, ao menos em certas áreas da vida social. Podese sugerir ainda que, nesse sentido, o campo intelectual e acadêmico teria problemas para desenvolver uma lógica interna (Miceli, 2005, p.132ss). Trata-se de velho - mas nem por isso desimportante - tema do pensamento latinoamericano, que se repõe de maneiras sutis e variadas hoje em dia, por razões "estruturais" de dependência acadêmica (Beigel, 2013).

Isso não quer dizer que não haja - em graus diversos - a "tradução" ou assimilação crítica das teorias e programas de pesquisa desenvolvidos no centro nessas periferias e semiperiferias, nem que seus problemas não sejam tematizados, ao menos a partir do momento em que certo grau de amadurecimento da vida intelectual e acadêmica é alcançado nos países que as compõem, como é o caso dos latino-americanos. Aquela dificuldade de construção de autonomia ocorreria em função exatamente da inserção do país de maneira desfavorável, internacionalmente - isto é, de forma depen- 
dente. Isso significa que o campo seria fundamentalmente, ou em grande medida, heterônomo, com o prestígio que se confere à produção intelectual e científica ainda em larga medida concentrado nos principais circuitos de produção e publicação europeus e estadunidenses, ${ }^{4}$ não obstante esforços para, aqui e ali, romper com essa desigualdade de poder, específica da geopolítica do conhecimento.

Uma vertente francesa de interpretação da África, em oposição a teorias simplistas da dependência - que a definem como se exercendo basicamente de fora para dentro, como, no caso, de um modo geral, nas teorias da dependência, dos poderes ocidentais -, propôs outra solução para esse tipo de problema (Bayart, 1989). Fala-se, assim, de extroversão, conceito por meio do qual se buscou acentuar os elementos internos que fazem com que um país esteja voltado para o exterior. Não nos parece que seja o caso de opor essas duas perspectivas. Se tomarmos os melhores exemplos das teorias da dependência e a pensarmos como sendo, em grande medida, articulada por forças internas (Cardoso e Faletto, 1970), isso se faz compatível com a ideia de extroversão, que não deve descurar, por outro lado, do exercício real das forças externas na determinação - heterônoma por parte daqueles que as sofrem - dos países submetidos ao domínio de pode놓 res coloniais, imperialistas ou algo do gênero. Seus campos seriam assim, ao mesmo tempo e em função das mesmas relações, dependentes extrovertidos, em parte como resultados de Qै processos que têm seu polo dinâmico fora desin ses países, em parte pela forma como se estruc tura a vida intelectual dentro deles próprios.

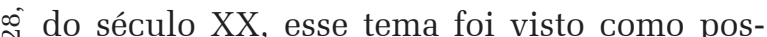

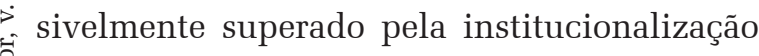
das ciências sociais nos diversos países da América Latina e pela formação de um campo

I Um exemplo claro disso hoje, no Brasil, mas também em boa parte dos países latino-americanos, é o fomento de uma política de internacionalização que não problematiza como, para que e para onde se internacionalizar, assumindo os grandes centros e as publicações em inglês como s modelo. de pesquisa e de debates internos. Na discussão, apareceram, com destaque, Guerreiro Ramos, Florestan Fernandes, Gino Germani, Rodolfo Stavenhagen, Pablo González Casanova, entre outros. Curiosamente, com o desmonte do campo intelectual e do intercâmbio da sociologia latino-americana a partir da ascensão das ditaduras, a questão retrocedeu na prática, com algumas exceções. ${ }^{5}$

A relação entre as ditaduras e o desmonte intelectual é, no entanto, ambivalente: por um lado, os regimes militares perseguiram e cassaram muitos intelectuais, obrigando-os, não poucas vezes, a deixarem seus respectivos países. Alguns dos principais centros regionais de produção da sociologia na América Latina se mantiveram com dificuldades ou inclusive fecharam (caso do Centro Latino-americano de Pesquisa em Ciências Sociais, CLAPCS, com sede no Rio de Janeiro ${ }^{6}$ ). Por outro lado, de forma paradoxal, o exílio serviu não somente como um espaço de luta internacionalista, mas também como espaço de convergência intelectual, o que rendeu, em alguns casos, colaborações intelectuais importantes, embora sempre presas na fronteira instável da condição do exilado.

Desse modo, a heteronomia - dependência e extroversão - do campo intelectual latino-americano aumentou novamente. Embora haja esforços, hoje, para diminuí-la, no Brasil, isso continua sendo forte e o debate intelectual, bastante débil. Pouco parece fazer por ele a introdução de certas correntes que curiosamente se difundem do exterior para cá, mesmo se capitaneadas por intelectuais latino-americanos, na criação de um ambiente intelectual relativamente autônomo, o que, obviamente, não prescinde de um diálogo intenso com o exterior, em particular com outros espaços periféricos.

\footnotetext{
${ }^{5}$ Para discussão suplementar e uma seleção dessas exceções ver, por exemplo, Domingues e Maneiro, 2006

${ }^{6}$ O NETSAL está realizando, com apoio financeiro da FAPERJ, uma grande pesquisa sobre o CLAPCS e os estudos latino-americanos no Brasil. Para um panorama inicial da pesquisa, cf. Dossiê Temático NETSAL "Sociologia latino-americana: originalidade e difusão”, no. 4, dezembro de 2014. Disponível em: http://netsal.iesp.uerj.br/images/ dossie/Dossie-Netsal_04.pdf
} 
Como já vimos, tampouco problematizações em torno de "epistemologias do Sul" parecem ajudar muito nesse sentido, sobretudo quando o próprio significado do termo permanece indefinido (equivocadamente tendendo, hoje, a significar conteúdos substantivos em que o não ocidental é negativizado, antes que se referindo a operações lógicas do pensamento e aos processos de construção do conhecimento). No primeiro caso, pode-se mesmo, de maneira sutil, reafirmar a heteronomia; no segundo, ou se esquece, ou se desconhece, o que apareceu, por exemplo, nos escritos de Houtondji (1977) sobre a pluralidade das abordagens fora do Ocidente e, sobretudo, que o que importa é a capacidade dos investigadores fora do centro de pensarem por conta própria, produzindo teorias de forma mais ou menos autônoma, apropriando-se do que a modernidade, de modo geral, produziu, aí incluídas a filosofia e as ciências sociais modernas.

Isso, obviamente, não nos dispensa de pensar epistemologicamente nossas teorias e conceitos e a relação que nossas próprias realidades - latino-americanas ou de qualquer outra parte do mundo - mantêm com as teorias e conceitos surgidos na Europa ou nos Estados Unidos. Mas parece ser na capacidade de autodeterminação intelectual que se jogam hoje, em grande parte, os destinos das ciências sociais brasileiras. Em outras palavras, em nossa capacidade de criar uma esfera própria de produção teórica - em diversos planos - e de debates propriamente intelectuais que recusem o culto excessivo de autores estrangeiros (nem se, por modismo, forem agora indianos ou moçambicanos), sem, por outro lado, apostar na afirmação de particularismos que falsificam a inserção do Brasil na trajetória humana e, em particular, seu pertencimento à modernidade.

Essas seriam formas de se manter, de fato, na subalternidade e de se mostrar incapaz de construir o que seria decisivo: a conformação de uma teia intelectual, um movimento instituinte e uma "subjetividade coletiva" de tipo específico, ${ }^{7}$ capaz de levar mais longe o debate próprio ao "mundo das ideias", que se centra hoje na universidade, e estendê-lo no plano da "esfera pública" e em outras conexões.

Torna-se, portanto, fundamental uma capacidade de dinamização interna mais acentuada - que pouco tem a ver com os critérios de avaliação, burocratização e normatização das agências governamentais, mas sim com o próprio debate intelectual -, ainda que sejam importantes também a permeabilidade às demandas da sociedade em geral e a conformação de redes mais amplas com agentes externos ao mundo universitário (com movimentos sociais, partidos, imprensa - hoje um nó extremamente problemático -, editoras, etc.). Há vários tipos de intelectual, sem dúvida; mas, embora haja inúmeros "sistemas peritos" e aqueles que são "intelectuais orgânicos" dos mais diversos tipos de organizações e movimentos, essa é uma atividade que tem seus requisitos e lógica própria.

As especificidades das áreas de pensamento e pesquisa precisam ser preservadas e valorizadas, tendo hoje o mundo intelectual seu centro na própria universidade. Inevitavelmente isso ocorre em seu âmbito e num momento em que a desvalorização do pensamento crítico - afora em suas versões mais pragmáticas - parece ser uma prioridade da "racionalização" dos sistemas políticos (incluídos aí os partidos) e do capitalismo. O contrário hoje caracteriza, em grande medida, nossa vida universitária, altamente institucionalizada, relativamente internacionalizada (de forma subalterna) e pouco afeita ao debate intelectual propriamente dito.

Há tradições nacionais diversas e não caberia pensar em uma autonomia do campo intelectual ao estilo da França do século XX,

${ }^{7}$ Esse conceito de sistema social, desenvolvido por Domingues alhures, nos parece permitir uma construção mais flexível que as de "espaco social” e "campo" de Bourdieu, que se mostram algo rígidas e pré-determinadas. No segundo caso, evidencia, ademais, tendencialmente, um fechamento excessivo sobre si mesmo, além dos problemas relativos à própria definição de agente que se encontra em sua teoria, demasiadamente determinado pelo habitus, cujas origens são, porém, obscuras. 
cujo legado, de todo modo, não é desprezível. ${ }^{8}$ Isso hoje, talvez, seja um imperativo das ciências sociais brasileiras, em particular se um campo de debate é mais bem estruturado do que o que temos presentemente, não obstante as múltiplas atividades das associações científicas das áreas de ciências humanas. Isso é o que nos facultaria melhor inserção, inclusive nas discussões públicas. Mas, sobretudo, é importante ser capaz de, nessa nossa particular situação brasileira de semiperiferia, avançar intelectualmente em termos de uma relação mais equilibrada tanto com o centro como com os demais países semiperiféricos e os propriamente periféricos. Não se trata apenas de produzir profissionalmente, senão de gerar uma discussão mais ampla sobre nossa trajetória, inserida em um mundo cada vez mais complexo. Como é sabido, esse é problema que se repõe. Daí a importância de, por um lado, atualizar, como faremos a seguir, a reiterada discussão sobre os circuitos internos. E, por outro, de construir, cumulativamente, nosso próprio espaço de debate, em vez de nos rendermos à extroversão ou à dependência, em suas mais diversas e inclusive disfarçadas manifestações.

\section{Os circuitos internos como comuni- dades nacionais imaginadas}

Como criar um debate intelectual próprio? É possível gerar um circuito interno na sociologia periférica? Ele deveria ser necessariamente nacional? Essas são questões centrais do debate latino-americano de meados de século XX que ainda ressoam na atualidade. A despeito da circulação regional e global, as : ciências sociais foram sendo forjadas nacionalmente, desde seus inícios, como "comunidades imaginadas". A analogia que aqui fazemos ao já clássico livro de Benedict Anderson (1991) deve-se ao fato de que a institucionalização de disciplinas como a sociologia ou a antropolo-

${ }^{8}$ (Bourdieu, 2012, p. 348-51) com referência ao embuste dos "novos filósofos". gia, em diversos contextos nacionais, sempre apelou para um campo ou circuito "interno" (lido, em geral, como sinônimo de nacional) de produção e circulação das ideias e dos debates. Essas comunidades científicas nacionais imaginadas baseiam-se, em primeiro lugar, na língua, embora a existência de uma mesma língua não implique necessariamente um diálogo sistemático entre duas comunidades nacionais (casos, por exemplo, de Brasil e Portugal, ou do Chile e da Espanha). Para além do idioma, importam também a canonização de autores e de referências nacionais, as tradições acadêmicas, as diferentes formas de inserção e relação com outras "comunidades imaginadas nacionais", bem como os circuitos de divulgação próprios, como é o caso das revistas e periódicos científicos.

São "imaginadas" pelo caráter de sua construção, mas também pela relativa fragilidade dos elos de suas cadeias e de sua escassa coesão interna. Associações científicas e congressos nacionais foram criados também para permitir a socialização, o debate e a divulgação entre os cientistas sociais desses países, conquanto, na atualidade, apresentem-se mais como uma soma de agendas individuais que como espaço de debates orientados por uma agenda coletiva.

Duas observações devem ser feitas sobre a criação dessas comunidades científicas nacionais. Em primeiro lugar, essa delimitação ocorreu, muitas vezes, em contato direto com a reconfiguração das associações internacionais, ou seja, a partir de demarcações sobre o caráter nacional e internacional das disciplinas. A Sociedade Brasileira de Sociologia (SBS), por exemplo, foi criada em 1950, sob forte influência de um convite feito em 1949 pela Associação Internacional de Sociologia (ISA) ao então presidente da Sociedade Paulista de Sociologia (SPS), Fernando de Azevedo. A criação dos estatutos da ISA em 1949, após sua fundação no mesmo ano, sob os auspícios da UNESCO, no I Congresso Internacional, realizado em Oslo, estimulava a afiliação e a criação de associa- 
ções nacionais. Reunido no dia 19 de janeiro de 1950, um grupo de sociólogos pertencentes à SPS decide pela criação da SBS para permitir o "estabelecimento de contatos entre sociólogos brasileiros e estrangeiros, bem como dos sociólogos brasileiros dentre si". ${ }^{9} \mathrm{Em}$ segundo lugar, o caráter do "nacional" varia muito de acordo com a posição dos países na divisão internacional dos sistemas científicos e do trabalho intelectual. Por um lado, a "dependência acadêmica” (reforçada com frequência, internamente, pelas políticas educativas, pelas instituições de pesquisa e pelo próprio Estado) não pode ser negligenciada em sua capacidade de reproduzir assimetrias na produção e difusão da sociologia entre os diversos países (Sabea e Beigel, 2014). Por outro, torna-se importante distinguir, no terreno político, os nacionalismos do centro dos nacionalismos periféricos, bem como examinar suas implicações em termos intelectuais. Quando o nacionalismo se constitui como "identidade periférica", seja de uma comunidade política (Beigel, 2004), seja de uma comunidade científica (Ramos, 1957), as consequências são marcantes.

Isso não significa que um circuito interno ou um campo autônomo seja necessariamente sinônimo de uma sociologia nacional; mas tão importante como examinar a posicionalidade do pesquisador e de seu lugar de enunciação é analisar as situações específicas envolvidas nesse processo. Guerreiro Ramos, por exemplo, era consciente da importância de considerar tanto o caráter periférico do Brasil como nação, como o cunho "circunstancial" do nacionalismo. Isso tem duas implicações diretas: em primeiro lugar, a busca da construção de uma sociologia brasileira (e isso valeria para qualquer sociologia nacional periférica)

${ }^{9}$ Informação retirada da Ata de Fundação da SBS, disponibilizada pela própria sociedade. Além de Fernando de Azevedo, participaram da reunião de fundação Maria Isaura Pereira de Queiroz (responsável por lavrar a ata), Antônio Candido, Florestan Fernandes, Octavio da Costa Eduardo, Herbert Baldus, Azis Simão, Donald Pierson, Antônio Rubbo Muller, Juarez Lopes, Levi Cruz, Oracy Nogueira, Sergio Buarque de Hollanda, Mauro Brandão Lopes, Maurício Segall, Lucula Herrmann, Gioconda Mussolini, Mário Wagner Vieira da Cunha, Egon Schaden e Roger Bastide. em termos de autonomia não pode se confundir com um "nacionalismo metodológico" (Beck, 2003; Chernilo, 2007). Em segundo lugar, a adoção do nacionalismo como ideologia seria um imperativo sempre contextual (naquele momento conduzido pela primazia da lógica populista e desenvolvimentista).

No tocante ao primeiro elemento, podese dizer que, a despeito de seu nacionalismo radical, que tem consequências sérias, inclusive em sua proposta de "redução sociológica", Ramos buscou, reconhecendo o caráter concreto da nação e depois, retrospectivamente, de modo sistemático, não naturalizar o Estado-nação como uma unidade analítica dada, procurando, ao contrário, observar sua historicidade e sua espacialidade, pois a escala nacional (assim como qualquer outra escala, seja ela local, regional ou global) é uma construção sócio-histórica. Por outro lado, deve-se reforçar o caráter situacional e instrumental do nacionalismo de Ramos. O próprio autor deixou claro, em entrevista concedida a Lucia Lippi, poucos meses antes de seu falecimento, que seu nacionalismo era um "nacionalismo de ocasião" (Oliveira, 1995, p.157).

Uma consequência interessante disso é que, embora Ramos (1957) não negasse o caráter universal da sociologia, sugeria que a sociologia deveria refletir as circunstâncias (nacionais) de sua produção. Seus argumentos são ricos, mas contraditórios. Por um lado, sua perspectiva "brasileira" não se restringe à defesa da associação entre cultura nacional e uma perspectiva particular. Por outro, sua crítica ao internacionalismo proletário e ao marxismo-leninismo a partir da qual construía, em Mito e Verdade da Revolução Brasileira, uma defesa do revisionismo, era mais problemática. Isso porque, embora Ramos (1963) fosse cuidadoso com os perigos do isolacionismo e da exaltação romântica e ingênua do nacional, acabou construindo uma fronteira algo rígida entre o nacionalismo e o internacionalismo, o que impediu uma maior aproximação com o pensamento sociológico regional. 
É verdade que A Redução Sociológica foi traduzida para o espanhol de forma quase imediata (1959) no México, que Ramos foi nome polêmico e de destaque no II Congresso Latino-americano de Sociologia de $1953,{ }^{10}$ que o pensamento cepalino influenciou fortemente o autor; e que ele alude, em vários de seus escritos, à "sociologia latino-americana”. No entanto, faz isso como ressonância dos problemas brasileiros e sem dialogar com a produção sociológica regional. ${ }^{11}$ Isso não deixa de ser curioso pela proximidade de algumas de suas propostas com a de outros autores latino-americanos. Rodolfo Stavenhagen, por exemplo, um dos principais sociólogos mexicanos, sempre buscou emoldurar suas interpretações em um escopo latino-americano. Foi diretor geral do CLAPCS no Rio de Janeiro, entre 1962 e 1964, período em que viveu no Brasil, e buscou combinar uma crítica epistemológica e a visão da descolonização da sociologia (Stavenhagen, 1971) com uma sólida construção teórica sobre "colonialismo interno", questão agrária e desenvolvimento (Stavenhagen, 1963). Sua aproximação processual para entender as matrizes de relações sociais e das classes sociais, seu método totalizante e a defesa de uma sociologia militante, através da teorização indutiva orientada empiricamente pela ação (Stavenhagen, 1965) são elementos cruciais de sua obra 농 que o aproximam de Ramos. Outras semelhanते ças podem ser encontradas com aportes de outros destacados sociólogos latino-americanos dos anos 1950 e 1960 (como o também mexicaê no Pablo González Casanova ou o colombiano

¿ ${ }^{10}$ Dentro da atual revitalização do pensamento de Ramos, $\infty$ uma interessante agenda de pesquisa que se abre seria a

$\stackrel{\sim}{*}$ análise da recepção do autor na América Latina e, parti-

$>$ cularmente, no México, onde influenciou, entre outros,

ثิ os teóricos da dependência, alguns dos quais haviam sido

T. seus alunos no Brasil, como foram os casos de Ruy Mauro Marini e Theotônio dos Santos.

क ${ }^{11}$ Ramos manteve, no entanto, uma proximidade bastante mais forte com a intelectualidade africana, sendo a negri-

\} tude e a mobilização instrumental do discurso nacionalis-

ta (caso de Nyerere na Tanzânia, entre outros), e ao mesmo

tempo pan-africanista (Nkrumah, 1965) elementos funda-

mentais desses vínculos, que acabaram aproximando-o

também, como é sabido, do movimento negro.
Esse é o caso paradigmático do peruano José Carlos Mariátegui, que, em 1928, escrevera seu emblemático livro Sete ensaios de interpretação da realidade peruana. Exemplar por sua apropriação crítica do marxismo para a análise nacional peruana, Mariátegui foi capaz, como poucos, de analisar a formação econômico-social latino-americana dentro de seu particular desenvolvimento histórico, desvinculando-se de olhares eurocêntricos. Assim como Ramos, e a despeito das diferenças de enfoques, Mariátegui não se contentava em criticar o eurocentrismo, buscando formular uma teoria social alternativa, ao menos substantivamente, pois se mantinha firmemente nos quadros do marxismo (qualquer que fosse sua compreensão dele em plano mais filosófico), afim à realidade peruana e latino-americana. Perica (2010), em interessante estudo sobre a recepção tardia e tímida de Mariátegui no Brasil, assinala que o primeiro a mencionar o autor peruano no Brasil foi justamente Ramos, em 1941, que reivindicara seu "método".

\section{A (re)construção de teoria na periferia}

Em uma mística de encerramento de um curso de formação política com lideranças de movimentos sociais latino-americanos, um militante boliviano grita, após várias palavras de ordem contra o imperialismo e pela unidade da luta social na América Latina: iPor la descolonización! iAbajo el eurocentrismo! Escuta-se, logo em seguida, um sussurro irônico em português: E vamos colocar o que no lugar? Com essa anedota, iniciamos esta última parte do presente artigo, indagando sobre as possibilidades de avançar com uma agenda instituinte do pensamento crítico que busque formular novas concepções teórico-metodológicas acordes com a realidade dos países periféricos.

Não há consenso entre as diversas correntes coexistentes nas sociologias que contemporaneamente questionam o entendimento do que é teoria, nucleada nos países centrais, e 
nem mesmo de como produzi-la. Para Connell (2007, capítulo 2; 2012), teoria é aquilo que se produz no Norte. Para além desse fundamental reconhecimento de quem produz e quem consume teoria, a autora avança, no entanto, na problematização de que a produção de uma teoria geral nas metrópoles está vinculada a certos pressupostos e posicionamentos geopolíticos. Se a teoria geral busca propor uma interpretação abrangente da sociedade e oferece conceitos que transcendem uma sociedade específica no tempo e no espaço, é, de fato, crucial avaliar, em sua elaboração, a contingência, a unidade analítica ponderada pela diversidade social, o dinamismo, os entrelaçamentos e correlações de forças e uma perspectiva mais relacional das coordenadas espaço-temporais.

Criar novas fórmulas para pensar a teoria social, e particularmente a teoria crítica, é algo crucial. No entanto, com algumas exceções, esse não parece ser o propósito central da maioria das formulações pós-coloniais, muitas das quais, de fato, negam a possibilidade de qualquer teoria geral. Por exemplo, Boaventura de Sousa Santos, ainda que sociólogo e praticante da disciplina, de fato, há décadas, nega a relevância de construir uma nova teoria geral, ou, inclusive, outro tipo de ciência social, pois considera que, "sem uma crítica ao modelo de racionalidade ocidental dominante [...], todas as propostas apresentadas pelas novas análises sociais, por mais alternativas que se considerem, tenderão a reproduzir o mesmo efeito de ocultação e descrédito" (Santos, 2002, p.238). Sua proposta de uma "razão cosmopolita" e da tradução, como alternativa à teoria geral, termina por ser mais retórica do que concreta.

A tradução e a busca de inteligibilidade global constituem, em nosso entendimento, um elemento importante para a reconstrução de uma teoria social crítica, e não uma alternativa à teoria geral. É preciso estar atento, nesse sentido, ao perigo político e teórico de que algumas visões da periferia, limitadas e circunscritas a determinadas lógicas sociais e culturais, virem a mesa do "privilégio epistê- mico”. De resto, vale indagar, o que entender por epistemologia? Para muitos aparece como algo concreto; nesse sentido há uma resposta clara sobre o que seria uma nova epistemologia nas ciências sociais, alterando-se, então, os sinais da desvalorização do colonial ou periférico ante o colonizador ou central (Patel, 2015). Mas o que importa aqui realmente são as operações lógicas que subjazem à produção do conteúdo, não ele mesmo, embora haja, inevitavelmente, uma dialética entre esses dois aspectos: destacam-se, nisso, o papel das "representações" e como se constroem, a relação entre sujeito e objeto, a operação das analogias e das categorias de análise no processo de produção do conhecimento, a relação entre concreto e abstrato, empírico e teórico, explicação e compreensão, etc. Nesse sentido, é verdade: a sociologia, embora possa aprender de outras fontes e possa querer superar a própria modernidade nas versões radicais da teoria crítica, segue sendo uma ciência moderna. Mesmo antropólogos ansiosos por aprender com seus "objetos" de pesquisa ou sua reconstrução hermenêutica terminam por aceitar, com certa torção de seu projeto íntimo, sua inserção no universo científico da modernidade. ${ }^{12}$ Mas, deve-se frisar: ser uma disciplina moderna não implica, de maneira alguma, uma aliança com um cartesianismo ultrapassado e caricatural, pois a modernidade é muito mais plural que isso; nem a apologia da ciência sem mais nem menos, nem a celebração acrítica da modernidade. Tampouco significa uma recusa a reconhecer outras formas de conhecimento, baseadas em outras epistemologias, como aquelas que talvez se calcassem algo próximo ao que consistia o pensamento selvagem, a "ciência do concreto”, para Lévi-Strauss (1962).

Ramos não discutiu essas questões, nesta chave, mas não estava desatento para problemas semelhantes. ${ }^{13}$ Diferentemente da${ }^{12}$ Como Viveiros de Castro, 2009, que tem, por outro lado, o mérito de pôr, de maneira correta, a questão das epistemologias, a partir da tradição lévi-straussiana e ideias de Foucault

${ }^{13}$ As reflexões a seguir estão baseadas, particularmente, 
queles que falam de uma "sociologia indígena" como referência a uma lógica particular de pensamento autóctone, ele utilizava a noção de "sociologia indígena" como sinônimo de sociologia brasileira que, como toda ciência nacional, seria universal, pois acreditava que a "universalidade da ciência não impede que a sociologia se diferencie nacionalmente" (Ramos, 1995, p.38 e p. 44-45). Segundo Ramos, a teoria social deve estar sempre enraizada no espaço e no tempo, sendo fundamental o manejo das teorias estrangeiras, embora não como norma, critério ou fim em si mesmo, mas como subsídio, ou seja, "como meros pontos de partida para novas formulações mais consentâneas com os fatores reais” (Ramos, 1995, p.126).

A relação entre teoria e prática e entre o momento político e a teorização da sociedade foi algo eminente para Ramos, motivo pelo qual, embora sua "sociologia em mangas de camisa" tenha sido frequentemente subestimada devido a seu caráter ideológico, sugeriu distinguir entre dois tipos de teorização da realidade social: a "teorização ideológica” e a "teorização sociológica” (Ramos, 1995, p. 61-64). Enquanto a primeira seria sempre sectária, por expressar e justificar os interesses particulares de um grupo ou de uma classe, a segunda resultaria de uma atitude crítica e autocrítica, nuançada, que busca sempre, a partir de um condiciona$\stackrel{20}{a}$ mento histórico-social, formular uma concepసั. ção de sociedade atenta a todas suas tendências constitutivas. sujeito se compenetram e a objetividade é sem-

nos textos Tema da transplantação na sociologia brasileira

(1954), Cartilha brasileira do aprendiz de Sociólogo (1954),

Enteléquias na interpretação (1954) e Crítica da sociologia

brasileira (1957), presentes em seu livro Introdução crítica

à sociologia brasileira. Utilizamos tanto a versão original de 1957 como a versão reeditada pela Editora da UFRJ em 1995, com prefácio de Clóvis Brigagão. pre perspectiva e situacional, pois o homem é um "ser em situação", como costumava dizer o autor.

A construção de uma sociologia crítica das sociedades periféricas, deveria fugir de alguns problemas recorrentes da sociologia na periferia: (a) o olhar simétrico e sincrético com a produção europeia e norte-americana; b) o dogmatismo e a utilização de argumentos de autoridade a partir da justaposição de textos de autores prestigiosos dos países centrais; c) o dedutivismo, calcado na cópia e na abstração da contingência histórica; d) a alienação, carregada de um tom pejorativo, derivada da ausência de esforços em promover a autodeterminação das sociedades periféricas; e) a inautenticidade, derivada da utilização de marcos pré-fabricados e de conceitos, métodos e técnicas desenraizadas (Ramos, 1995, p. 38-44). Por trás desses "nãos" há muitos "sins": contra a coisificação dos fatos sociais, propõe-se a análise de processos; contra a "transplantação", tema por excelência da sociologia na periferia, sugere-se o procedimento crítico-assimilativo da experiência estrangeira; contra o dedutivismo eurocentrado, apresenta-se o método empírico-indutivo que busque partir da situação concreta para o plano teórico.

Há, em Guerreiro Ramos, tanto uma "atitude sociológica” como uma proposta de transportar, para o plano abstrato dos conceitos, as realidades históricas efetivas. Essa proposta intelectual se cristaliza, posteriormente, em $A$ Redução Sociológica, em que ele busca conciliar a crítica epistemológica e a construção teórico-metodológica. A Redução é uma das mais conhecidas contribuições de Ramos no tocante à construção de uma teoria na periferia. Embora existam várias leituras possíveis dessa obra, pode-se afirmar que ela contêm não somente uma dimensão político-epistêmica, como também uma proposta teórico-metodológica. Em outras palavras, ele estava preocupado com um duplo movimento: por um lado, um movimento destituinte, de crítica à assimilação acrítica do "pensamento sociológico alieníge- 
na”, que assumia a premissa, política e normativa, da necessidade de uma "descolonização da mentalidade” (Chinweizu, 1987); por outro, um movimento instituinte de reconstrução teórica, baseado em uma proposta metodológica preocupada com a construção de um método de assimilação crítica para abordar a transposição de conhecimentos de um contexto social para outros.

Na verdade, deve-se assinalar que a obra não está isenta de problemas, entre os quais se destaca sua formulação epistemológica - eminentemente moderna -, calcada na fenomenologia (que se seguiu, ainda que se mantendo em parte em seus quadros, à crise do cartesianismo). Sem dúvida, a formulação de Ramos é ambígua, mas se expressa basicamente na ideia de que é preciso que o sociólogo se livre de suas pressuposições, mediante uma "redução" que limpe sua mente de pré-noções, de modo que possa inserir sua consciência diretamente na realidade nacional. Completa a ideia a tese de que à sociologia importada estaria reservado papel "subsidiário", sem que se diga exatamente qual e sem que sua reconstrução, em especial no que diz respeito à ampla bagagem que dela inevitavelmente herdamos, seja discutida realmente (Ramos, 1965).

Obviamente, Ramos não é o primeiro a pensar essa questão, que está, como vimos, no cerne da sociologia latino-americana de meados do século XX. Acontece que aquela sociologia periférica vinha acompanhada de um momento histórico e geopolítico no qual a decadência do colonialismo e a crítica ao imperialismo tiveram um poder agregador em termos políticos e intelectuais. Hoje, a geopolítica das resistências é muito mais fragmentada, a modernidade mais complexa e as propostas de alternativas políticas e intelectuais têm menor capacidade, a despeito da maior facilidade de difusão, de gerar agendas e circuitos coletivos em uma sociologia cada vez mais especializada.

\section{NOTAS FINAIS}

Guerreiro Ramos foi sociólogo brasileiro, polêmico e inovador, ainda que haja limites claros em sua obra, em particular de um ponto de vista substantivo. Embora tenha aberto caminhos instigantes, não deixou efetivamente um caudal de análises sistemáticas e duráveis sobre a sociedade brasileira, ao contrário de Florestan Fernandes, por exemplo, com quem sustentou polêmica memorável em relação à produção da sociologia e de teoria sociológica no Brasil (Ramos, 1965; Fernandes, 1958), estilo de debate que hoje muito nos faz falta e que, por isso mesmo, merece figurar na conclusão deste artigo. Mas, sobretudo nos termos das discussões a respeito de uma sociologia global e seu significado hoje, sua posição não pode ser ignorada.

Foi exatamente para inseri-lo nos quadros desse debate que este artigo se dedicou, reivindicando - em consonância com Ramos, não obstante quaisquer limites e divergências substantivas que se tenha assinalado - seu nome como um daqueles que, em meados do século passado, tinha clareza de nossos problemas, necessidades e potencialidades. Ou seja, trata-se de contribuição fundamental na direção da construção de uma sociologia de inspiração global, ainda que moldada a partir de quadros nacionais (e exatamente por isso, decerto diria ele). Muito mudou no debate desde então. Sua sofisticação aumentou consideravelmente, conquanto, por outro lado, tenha oferecido pouco recentemente no que se refere à prática concreta da sociologia. Nesse sentido, além de reconstruir a situação da sociologia global e reivindicar o nome de Ramos como seu aliado, este texto é também uma demanda para que avancemos para além da retórica e da teoria abstrata e ornamentalmente concebida, sem recusar a teoria, há que sublinhar, mais robustamente do que ele próprio admitiria.

Além disso, é mais do que evidente que uma das preocupações suas era exatamente criar um "campo" intelectual autônomo, pre- 
nhe de compromissos com a situação brasileira, ainda que, por outro lado seu nacionalismo, até certo ponto justificado para a época, possa ser facilmente considerado excessivo. A extroversão continua viva, embora o tema de nossa capacidade e desejo de pensar por nós mesmos e avançar para além da posição de consumidores intelectuais, especialmente de teorias, tensione essa localização e essa atitude problemáticas. Eis esforço em que cumpre perseverar.

O engajamento conceitual na realidade em que vivemos e a interpretação dessa realidade pela teoria são imprescindíveis, se quisermos atualizar a sociologia em termos globais e críticos, científicos e emancipatórios. Queremos crer que Guerreiro Ramos, apesar de prováveis discordâncias e da polêmica que inevitavelmente o seduziria, estaria de acordo, no fundamental, com essa concepção. Recebido para publicação em 01 de novembro de 2014
Aceito em 11 de dezembro de 2014

\section{REFERÊNCIAS}

ADESINA, Jimi. Sociology and Yoruba Studies: epistemic intervention or doing sociology in the "vernacular?. African Sociological Review, Dakar (CODESRIA), v. 6, n. 1, p. 91-114, 2002.

AGNEW, John; CORBRIDGE, Stuart. Mastering space: s hegemony, territory and international political economy. of Londres: Routledge, 1995.

\& AKIWOWO, Akinsola. Universalism and indigenisation. Sociological theory: introduction. International Sociology, Londres, v. 3, n. 2, p. 155-160, 1988.

胥

ANDERSON, Benedict. Imagined communities: reflections $\hat{0}$ on the origin and the spread of nationalism. Londres: ș Verson, 1991.

¿. BAYART, François. L'État en Afrique. La politique du ventre. ๓ं Paris: Fayard, 1989.

\& BECK, Ulrich. Toward a new critical theory with a cosmopolitan intent, Constellations. New York, v. 10, n. 4, $\stackrel{\infty}{\sim}$ p. $453-468,2003$

$\therefore$ BEIGEL, Fernanda. Las identidades periféricas en el of fuego cruzado del cosmopolitismo y el nacionalismo. In: VVAA, Pensar a contracorriente. La Habana: Ediciones de तु Ciencias Sociales. p. 169-199, 2004.

(Org.) The politics of Academic Autonomy in Latin America. Londres: Ashgate, 2013.

BHAMBRA, Gurminder. The possibilities of, and for, Global Sociology. Political Power and Social Theory, Boston, v. 24, p. 295-314, 2013.
BOATCA, Manuela; COSTA, Sérgio; GUTIÉRREZRODRÍGUEZ, Encarnarción (Orgs.) Decolonizing European Sociology: trans-disciplinary approaches. Aldershot, Ashgate, 2010.

BOURDIEU, Pierre. Le Règles de l'art. Genèse et structure du champ litéraire. Paris: Seuil, 1992.

. Sur L'État. Cours au College de France, 1989-1992. Paris: Raison d'agir e Seuil, 2012.

BRINGEL, Breno. Ativismo transnacional, o estudo dos movimentos sociais e as novas geografias pós-coloniais. Estudos de Sociologia, Recife, v. 16, p. 185-215, 2011.

. Social movements and contemporary modernity: internationalism and patterns of global contestation. In: BRINGEL, Breno; DOMINGUES, José Maurício (Orgs.) Global modernity and social contestation. Londres e Nova Déli: Sage, p. 122-138, 2015.

; DOMINGUES, José Maurício. Movimentos sociais e teoria crítica: interseções, impasses e alternativas. In: BRINGEL, Breno; GOHN, Maria da Glória (Orgs.) Movimentos sociais na era global. Rio de Janeiro/Petrópolis: Vozes, p. 57-75, 2012.

; _. (Orgs.) Global Modernity and Social

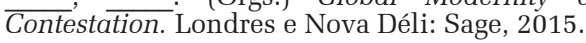

BURAWOY, Michael. For Public Sociology. American Sociological Review, Washington D.C., v. 70, n. 1, p. 4-28, 2005.

Travelling theory, openMovements (openDemocracy), editado por Breno Bringel e Geoffrey Pleyers, Londres, março de 2015. Disponível em: https://www. opendemocracy.net/michael-burawoy/travelling-theory

CAIRO, Heriberto. A América Latina nos modelos geopolíticos modernos: da marginalização à preocupação com sua autonomia. Caderno CRH, Salvador, v. 21, n. 53, p. 221-237, 2008.

CAIRO, Heriberto; BRINGEL, Breno. Articulaciones del Sur Global: afinidade cultural, internacionalismo solidario e Iberoamérica en la globalización contra hegemónica, Geopolítica(s): Revista de Estudios sobre Espacio y Poder, Madrid, v. 1, n. 1, p. 41-63, 2010.

CARDOSO, Fernando Henrique; FALETTO, Enzo. Dependência e desenvolvimento na América Latina. Rio de Janeiro: Zahar, 1970.

CHAKRABARTY, Dipesh. Provincializing Europe: postcolonial thought and historical difference. Princeton: Princeton University Press, 2000.

CHERNILO, Daniel. A social theory of the nation state. The political forms of modernity beyond methodological nationalism. Londres: Routledge, 2007.

CHINWEIZU, Ibekwe. Decolonising the African mind. Lagos: Pero Press, 1987.

CONNELL, Raewyn. Southern theory. The global dynamics of knowledge in social science. Cambridge: Polity Press, 2007.

A iminente revolução na teoria social, Revista Brasileira de Ciências Sociais. São Paulo, v. 27, n. 80, p. 9-20, 2012.

DEVÉS-VALDÉS, Eduardo. Pensamiento periférico: Asia, África, América Latina - Eurasia y algo más. Una interpretación global. Buenos Aires: CLACSO e IDEAUSACH, 2014.

DOMINGUES, José Maurício. Do Ocidente à modernidade. Intelectuais e mudança social. Rio de Janeiro: Civilização Brasileira, 2003.

América Latina e a modernidade contemporânea. Belo Horizonte: Editora UFMG, 2009. 
Teoria crítica e (semi)periferia. Belo Horizonte: Editora UFMG, 2011.

Modernidade global e civilização contemporânea: para a renovação da teoria crítica. Belo Horizonte: Editora UFMG, 2013.

DOMINGUES, José Maurício; MANEIRO, María (Orgs). América Latina hoje. Rio de Janeiro: Civilização Brasileira, 2006.

FERNANDES, Florestan. A etnologia e a sociologia no Brasil: ensaios sobre aspectos da formação e do desenvolvimento das ciências sociais na sociedade brasileira. São Paulo: Anhambi, 1958.

GERMANI, Gino. Desarrollo y estado actual de la sociología latinoamericana. Buenos Aires: Cuadernos del Boletín del Instituto de Sociología, 1959.

HOUTONDJI, Paulin J. Sur la "Philosophie Africaine". Paris: Maspero, 1977.

LAL, Vinay. Subaltern studies and its critics: Debates over Indian history. History and Theory, New Jersey, v. 40, p. 135-48, 2001

LÉVI-STRAUSS, Claude. La pensée sauvage. Paris: Plon, 1962.

MAIA, João Marcelo. Reputações à brasileira. O caso de Alberto Guerreiro Ramos. Sociologia \& Antropologia, Rio de Janeiro, v. 2, n. 4, p. 265-291, 2012.

MICELI, Sérgio. A noite da madrinha. São Paulo: Cia. das Letras, 2005.

MIGNOLO, Walter. The geopolitics of knowledge and the colonial difference. The south atlantic quarterly, Durham, v. 101, n. 1 , p. 57-96, 2002.

NKRUMAH, Kwame. Neo-colonialism, the last stage of imperialism. Londres: Thomas Nelson \& Sons, 1965.

OLIVEIRA, Lucia Lippi de. A sociologia do Guerreiro. Rio de Janeiro: Editora UFRJ, 1995.

RAMOS, Guerreiro. A problemática da realidade brasileira. In: Instituto Superior de Estudos Brasileiros (ISEB). Introducão aos problemas do Brasil. Rio de Janeiro: Departamento de Imprensa Nacional, p. 13-32, 1956.

Introdução crítica à sociologia brasileira. Rio de Janeiro: Andes, 1957 (versão original e versão reeditada pela Editora da UFRJ em 1995).

Mito e verdade da revolução brasileira. Rio de Janeiro: Zahar Editores, 1963.

A redução sociológica: introdução ao estudo da razão sociológica. Rio de Janeiro: Edições Tempo Brasileiro (2a edição, corrigida e aumentada), 1965.
PATEL, Sujata. The global transition and the challenge to social sciences. In: BRINGEL, Breno; DOMINGUES, José Maurício (Orgs.) Global modernity and social contestation. Londres/Nova Delhi, p. 36-50, 2015.

PERICAS, Luiz Bernardo. José Carlos Mariátegui e o Brasil. Estudos Avançados, São Paulo, v. 24, n. 68, p. 335-361, 2010 .

SABEA, Hanan; BEIGEL, Fernanda (Orgs.) Dependencia académica y profesionalización en el Sur. Perspectivas desde la periferia. Mendoza: Editora de la Universidad Nacional de Cuyo / Sephis, 2014.

SANTOS, Boaventura de Sousa. Para uma sociologia das ausências e uma sociologia das emergencias. Revista Crítica de Ciências Sociais. São Paulo, n .63, p. 237-280, 2002.

. Una epistemología desde el sur: la reinvención del co nocimiento y la emancipación social. México: Siglo XXI, CLACSO, 2009

SARKAR, Sumit. Writing social history. Nova Delhi: Oxford University Press, 1997.

STAVENHAGEN, Rodolfo. Clases, colonialismo y aculturación en América Latina. Centro Latino-Americano de Pesquisas em Ciências Sociais (CLAPCS), Rio de Janeiro, v. 6, n. 4, p. 63-104, 1963.

Siete tesis equivocadas sobre América Latina.

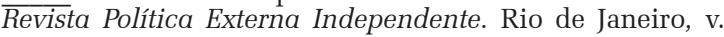
1, n. 1, 1965.

Sociología y subdesarrollo. México D.F.: Editorial $\overline{\text { Nuestro Tiempo, } 1971 .}$

TURNER, Bryan. From orientalism to global sociology, Sociology. Londres, v. 23, n. 4, p. 629-638, 1989.

VIVEIROS DE CASTRO, Eduardo. Metaphysiques cannibales. Paris: Presses Universitaires de France, 2009.

WANG Hui. Contemporary Chinese thought and the question of modernity. In: XUDONG Zhang (Org.), Whither China? Intellectual Politics in Contemporary China. Durham, NC and London: Duke University Press, 2001. 


\section{SOCIAL THEORY, EXTROVERSION AND AUTONOMY: impasses and horizons of (semi) peripheral contemporary sociology}

\author{
Breno Bringel \\ José Maurício Domingues
}

\section{THÉORIE SOCIALE, EXTROVERSION ET AUTONOMIE: les impasses et les horizons de la sociologie (semi)périphérique contemporaine}

\author{
Breno Bringel \\ José Maurício Domingues
}

This article analyzes the production of peripheral social theory in different geopolitical eras and stages of modernity, with a special focus on (semi) peripheral contemporary sociology. We argue that the current research agenda is focused on an intellectual movement of a criticism that fights Eurocentrism and modernity, however without being able to create systematic theoreticalmethodological formulations, as it had occurred in the middle of the twentieth century. We, therefore, seek to improve the basis for a more propositional instituting movement from two directions: on the one hand, by recovering the centrality of autonomous fields and aggregator circuits that may overcome intellectual extroversion; on the other hand, by analyzing, in a dialogue with Guerreiro Ramos, the possibilities of creating a theory in (semi)periphery as one of the main ways to undo more permanently the hegemony of theories from central countries and its customary use outside its original place.

KEYwords: Sociological theory. (Semi)periphery. Global modernity. Guerreiro Ramos. Epistemology.
Cet article analyse la production de la théorie sociale dans la périphérie au sein de différentes ères géopolitiques et phases de la modernité, en mettant tout particulièrement l'accent sur la sociologie semi(périphérique) contemporaine. On y argumente que la recherche actuelle tourne autour d'un mouvement intellectuel de critique libre de l'eurocentrisme et de la modernité mais qui n'arrive cependant pas à créer des formules théoriques et méthodologiques systématiques comme ce fut le cas au milieu du XXe siècle. On cherche donc à avancer au niveau de la base pour la construction d'un mouvement instituant qui propose plus à partir de deux tendances : d'une part, en récupérant la centralité de champs autonomes et de circuits adjoignants qui dépassent l'extroversion intellectuelle, et, d'autre part, en analysant, à partir d'un dialogue avec Guerreiro Ramos, les possibilités de construction d'une théorie dans la (semi) périphérie considérée comme l'une des principales clés pour déplacer, de manière plus permanente, l'hégémonie des théories des pays centraux et leur utilisation habituellement protocolaire en dehors de leur pays d'origine.

Mots-CLÉs: Théorie sociologique. Semi(périphérie). Modernité mondiale. Guerreiro Ramos. Épistémologie. de Madri, onde foi professor. Professor Adjunto do Instituto de Estudos Sociais e Políticos (IESP) da Universidade do Estado do Rio de Janeiro (UERJ) e Coordenador, juntamente com José Mauricio Domingues, do Núcleo de Estudos de Teoria Social e América Latina (NETSAL). Editor de DADOS Revista de Ciências Sociais e de openMovements, novo projeto de openDemocracy (www.opendemocracy. net/openmovements). Bolsista PROCIÊNCIA (UERJ), Jovem Cientista do Nosso Estado (FAPERJ) e bolsista de Produtividade em Pesquisa do CNPq. Publicações recentes: Global modernity and social contestation, editado com José Maurício Domingues. Sage, 2015; O MST e o internacionalismo contemporâneo (Eduerj, no prelo); Les mobilisations de 2013 au Brésil: vers une reconfiguration de la contestation. Bresil(s), v. 7, p. 7-18, 2015; Movimientos sociales y gobiernos en América Latina: nuevos escenarios, ejes de conflicto y tipología de relaciones. Cadernos de Trabalho NETSAL, v. 2, p. 1-21, 2014.

José Maurício Domingues - PhD em Sociologia pela London School of Economics and Political Science. Professor-pesquisador do IESP-UERJ. Bolsista de Produtividade do CNPq 1B e Cientista do Nosso Estado - FAPERJ. Suas áreas principais de pesquisa são teoria social, sociológica e crítica, e modernidade global. Publicações recentes: Modernidade global e civilização contemporânea. Para uma renovação da teoria crítica. UFMG, 2013; O Brasil entre o presente e o futuro. Mauad, 2013; Global modernity and social contestation, editado com Breno Bringel. Sage, 2015). 